\title{
Premature Lambs Rescued from Respiratory Failure with Natural Surfactant: Clinical and Biophysical Correlates
}

\author{
HARRIS JACOBS, ${ }^{(22)}$ ALAN JOBE, MACHIKO IKEGAMI, THEODORE GLATZ, SALLY J. JONES, \\ AND LUCIANO BARAJAS \\ Departments of Pediatrics and Pathology, Harbor-UCLA Medical Center, Torrance, California, USA
}

\begin{abstract}
Summary
Thirty-four Western mixed breed lambs were delivered prematurely at 120 days gestational age (term $=150$ days). Four lambs were sacrificed at birth, and four lambs were sacrificed with the onset of respiratory failure $\left(\mathrm{PCO}_{2}>\mathbf{8 0}\right.$ torr) at about $30 \mathrm{~min}$ of age. The remaining lambs were treated by tracheal instillation with $50 \mathrm{mg}$ of natural sheep surfactant lipid/ $\mathrm{kg}$ body weight. These lambs were sacrificed $10 \mathrm{~min}, 40 \mathrm{~min}, 1.5 \mathrm{~h}$ and $3 \mathrm{~h}$ after surfactant treatment. Frequent blood gas and compliance measurements documented the clinical responses of the lambs.

Lungs from treated lambs showed large increases relative to untreated lungs in air volumes as assessed by pressure-volume curves and by histology. However, the pressure-volume and histologic measurements did not distinguish between the posttreatment groups of lambs. Minimum surface tensions of alveolar washes fell from $>30$ dynes $/ \mathrm{cm}$ to 6.3 dynes $/ \mathrm{cm} 10 \mathrm{~min}$ after treatment and again rose to 21.6 dynes/cm within $3 \mathrm{~h}$. Minimum surface tensions correlated well with the $\mathrm{Po}_{2}$ values but not with the $\mathrm{PCO}_{2}$ values measured before sacrifice. The combination of dilated distal airways and atelectasis resulted from increasing surface tensions with time and mechanical ventilation and may explain the clinical deterioration without much change in the volume of gas within the airways.
\end{abstract}

\section{Speculation}

Treatment of respiratory distress syndrome by surfactant replacement may only be of temporary value in very ill premature babies. This may be secondary to inhibitors of surfactant function which enter the airways and to immaturity of supporting lung structures. This may manifest itself as respirator induced progressive dilatation of distal airways which are very inefficient at gas exchange.

Respiratory distress syndrome (RDS) of the premature neonate is considered to be due primarily to surfactant deficiency $(5,6)$. Clinical, biochemical, and histological features of RDS have been compared $(2,3,17)$. One approach to treatment of RDS is surfactant replacement. Attempts to administer surfactant or synthetic surfactant components into the airways by nebulization were not encouraging $(10,19)$. Surfactant suspensions have been administered by pharyngeal deposition before the first breath in premature rabbits (22), direct tracheal instillation in premature lambs $(4,16)$ and direct tracheal instillation in humans (12). Surfactant suspensions have dramatically improved a variety of measurements of pulmonary function. We studied and described the predictable responses of premature lambs given natural surfactant after resprpiratory failure was established (16). The response to natural surfactant lasted only about $3 \mathrm{~h}$ and clinical deterioration correlated with the appearance of protein in the airways and inhibition of the surface tension lowering properties of surfactant (14). To better define the course and nature of changes that occur after surfactant therapy, premature lambs in respiratory failure were treated with natural sheep surfactant and sacrificed at different time intervals after treatment. We compared the clinical data, minimal surface tensions of the alveolar washes, histologic appearance of the lungs, and pressure-volume curves of the lungs at sacrifice.

\section{MATERIALS AND METHODS}

Treatment protocol. Thirty-four Western mix breed lambs from twin and triplet pregnancies were delivered prematurely be cesarean section at 120-121 days gestational age (normal gestation 150 days). The lambs were assigned before delivery into one of six groups of four-seven lambs/group. Groups containing more than four lambs had the extra lambs added to insure a minumum of three lambs/group with technically adequate PV studies and histologic sections. Ewes were prepared and delivered as before (16). All lambs had an uncuffed $4.5 \mathrm{~mm}$ endotracheal tube placed surgically into the trachea. Five to $10 \mathrm{ml}$ of fetal lung fluid was aspirated and the endotracheal tube was clamped. Cord blood was drawn for blood gas measurements as each lamb was delivered. All lambs were weighed. One group of animals was sacrificed before the first breath. All other lambs were placed on pressure limited Sechrist infant ventilators. The ventilator settings were held constant throughout the experimental period at an $\mathrm{FIO}_{2}$ of 1.0 , a rate 30 breaths/min, $1 \mathrm{sec}$ inspiratory time, peak inspiratory pressure of $30 \mathrm{~cm} \mathrm{H}_{2} \mathrm{O}$, and positive end expiratory pressure of 2 $\mathrm{cm} \mathrm{H}_{2} \mathrm{O}(20)$. The lambs were dried superficially and placed under Air Shields Infant radiant warmers. Core temperature was monitored with a rectal temperature probe and maintained at $37-39^{\circ} \mathrm{C}$. Via an umbilical artery, a catheter was placed in the abdominal aorta through which $0.1 \mathrm{mg} / \mathrm{kg}$ pancuronium bromide (Pavulon, Organon) was given shortly after birth. The lambs received 100 $\mathrm{ml} / \mathrm{kg} / 24 \mathrm{~h}$ of $5 \%$ dextrose in water as a continuous infusion through the arterial catheter. This catheter was used for frequent arterial blood gas measurements and for continuous blood pressure and heart rate monitoring. Expiratory tidal volumes and compliance $/ \mathrm{kg}$ were measured intermittently and determined as before (16).

With the onset of ventilatory failure $\left(\mathrm{PCO}_{2}>80 \mathrm{~mm} \mathrm{Hg}\right)$, a second group of lambs was sacrificed. All the remaining lambs received by tracheal instillation $7 \mathrm{ml} / \mathrm{kg}$ of a water suspension containing $50 \mathrm{mg}$ of natural surfactant lipid/ $\mathrm{kg}$ body weight (13). The natural surfactant used to treat the lambs was isolated from alveolar lavage fluid of 16 adult sheep by centrifugation (16). Lambs were treated with a surfactant preparation which was a mixture of those isolated from several ewes. When tested at room temperature on a Whilhelmy balance, all preparations lowered the surface tension to less than 10 dynes $/ \mathrm{cm}$. The treated lambs 
were electively sacrificed with intracisternal lidocaine (4) at approximately $10 \mathrm{~min}, 40 \mathrm{~min}, 1.5 \mathrm{~h}$, or $3 \mathrm{~h}$ after surfactant therapy. Any lamb not showing at least a $100 \mathrm{~mm} \mathrm{Hg}$ increase in $\mathrm{PO}_{2}$ after therapy was discarded from analysis. Tidal volumes and arterial blood gases were measured immediately before sacrifice.

Pressure-volume curves. After sacrifice, the lungs were removed intact and weighted. The left lung was separated from the right lung, weighed and used for a pressure-volume (PV) curve. The temperature of the lung was maintained at $37^{\circ} \mathrm{C}$ as the lung was inflated with $1.9 \mathrm{cc}$ of air $/ \mathrm{min}$. Pressure was measured at regular time intervals with a water manometer in parallel with the lung. When the pressure reached $30 \mathrm{~cm} \mathrm{H}_{2} \mathrm{O}$, flow was reversed deflating the lung at the same rate. Volumes were corrected for the volume disreplacement of the system (4). The volume of air/g lung was plotted against pressure for inflation and deflation. From this plot we measured the enclosed volume (area) between the loops, the volume at maximum inflation, the residual volume at the end of deflation, the volume at $10 \mathrm{~cm} \mathrm{H}_{2} \mathrm{O}$ on the deflation limb of the $\mathrm{PV}$ curve and the \% of maximum volume remaining at $10 \mathrm{~cm}$
$\mathrm{H}_{2} \mathrm{O}$. We measured PV curves on 22 of the lambs with at least three PV curves being measured per group. Lungs of the other lambs were discarded because of air leaks.

Surface tension. An alveolar wash with normal saline was recovered from the right lower lobe for surface tension measurements with a Wilhelmy balance at room temperature. The alveolar wash was placed undiluted on the balance and cycled until a stable minimal surface tension was recorded (4). The quantity of phosphatidylcholine placed on the balance from each alveolar wash was measured by phosphate analysis (7) after lipid extraction (8) and thin layer chromatography (15). Surface tension measurements were made on alveolar washes from at least three lambs per group. A total of 28 lambs had surface tension measurements.

Histology. The bronchus to the right upper lobe was cannulated and the lobe was expanded to a pressure of $30 \mathrm{~cm} \mathrm{H}_{2} \mathrm{O}$ for about $15 \mathrm{sec}$. The lobe then was deflated to and held at a pressure of 10 $\mathrm{cm} \mathrm{H}_{2} \mathrm{O}$. The artery to the right upper lobe was cannulated and the tissue was fixed by perfusion with $10 \%$ phosphate buffered formaldehyde. Five micron sections were prepared from two
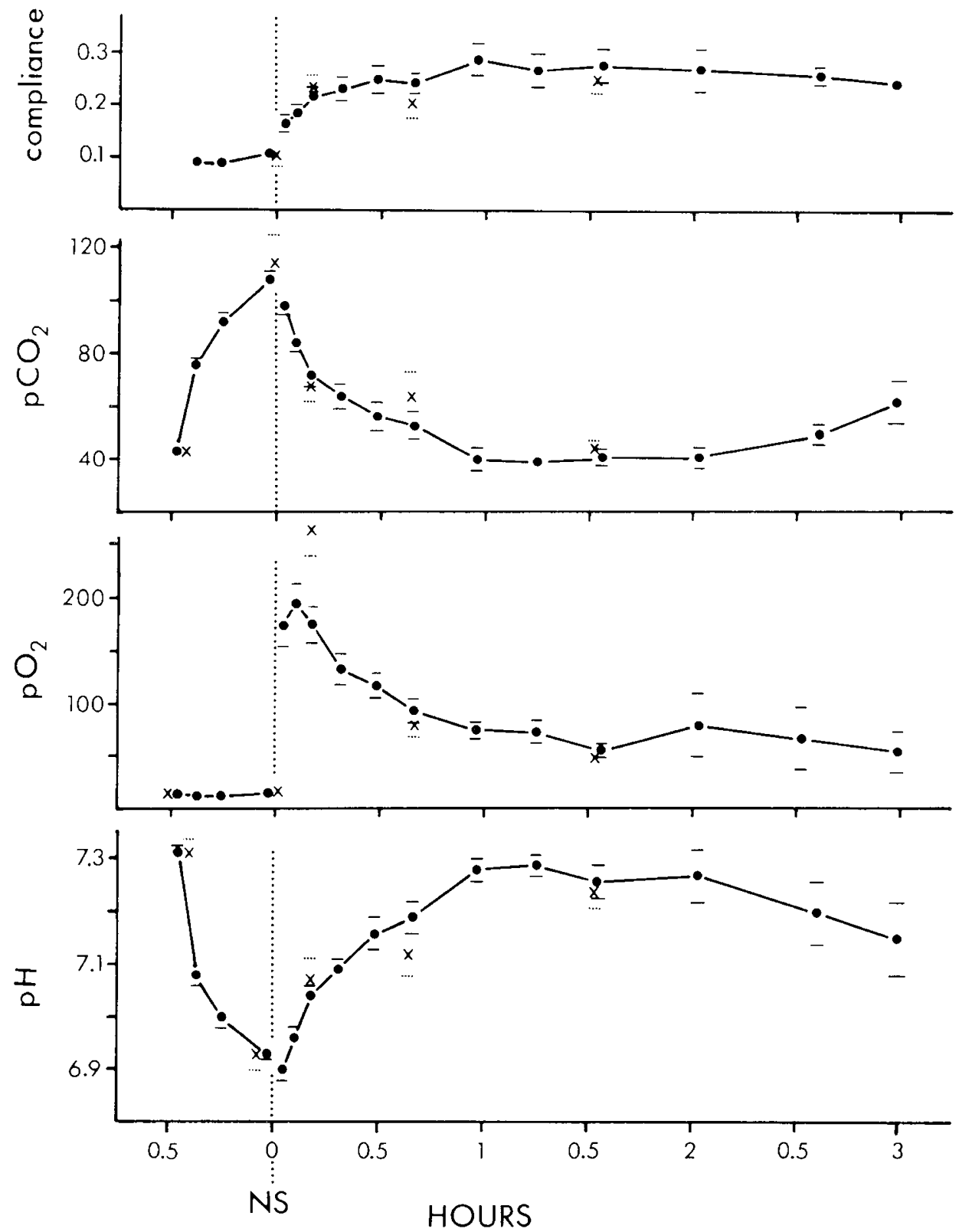

Fig. 1. Compliance/kg body weight, $\mathrm{PCO}_{2}$ (torr), $\mathrm{Po}_{2}$ (torr), and $\mathrm{pH}$ vs time in h after birth. Treatments with natural surfactant (NS) are indicated as 0 time by the dotted line. Mean values \pm S.E. for the groups of lambs at the time of sacrifice are given by $x$. Mean values \pm S.E. for all lambs still alive at the indicated times are given by solid dots connected by solid lines. The S.E. of the time intervals are all $\leq 1 \mathrm{~min}$. 
paraffin embedded tissue blocks from each right upper lobe and stained with Hematoxylin-Eosin. Three different areas of the two representative coded sections from each lung were photographed and enlarged to $25 \times 15.5 \mathrm{~cm}$ black and white prints $(\times 104$ magnification) by a pathologist unaware of the experimental protocol. Three different people placed different grids, each containing about 100 evenly spaced points, over each picture and counted the number of points falling over an air space $\geq 5 \times 5$ $\mathrm{mm}$ and the number of points falling over lung parenchyma. Percent aeration was expressed as points over air spaces divided by total points counted. Points falling over large vessels, bronchi or connective tissue bands were not counted.

All values are given as means \pm S.E. Statistical comparisons are by a two tailed Student's $t$ test corrected for multiple comparisons.

\section{RESULTS}

Clinical course of lambs. The mean birthweight of the lambs was $2.0 \pm 0.06 \mathrm{~kg}$. Two of 34 lambs had increases in $\mathrm{Po}_{2}$ less than 100 $\mathrm{mm} \mathrm{Hg}$ after surfactant therapy and are not included in the analysis. Their maximum $\mathrm{Po}_{2}$ response was less than $50 \mathrm{~mm} \mathrm{Hg}$. The variability in response was related neither to the surfactant preparation used nor to any other parameter measured before treatment. All results are based on the 32 lambs who responded adequately. Figure 1 shows clinical responses of the 32 lambs both by group and taken as a whole. Mean values for each group at the time of sacrifice are indicated by $x$. The curves give the mean values for all lambs still alive at the indicated times. With the single exception of the mean arterial $\mathrm{Po}_{2}$ of the lambs sacrificed 10 min after surfactant therapy, all group means were similar to the values for the rest of the lambs that were still alive. Hence, the timed sacrifice groups were representative of the entire group in terms of their response to natural surfactant. No animals were acidotic at birth (cord $\mathrm{pH}, 7.30 \pm 0.01$ ). The time from birth to treatment was very similar for all treated lambs $(26.3 \pm 1.4 \mathrm{~min})$. The general pattern of response was a rapid rise in the $\mathrm{PO}_{2}$ which fell concomittantly with improvements in $\mathrm{pH}, \mathrm{PCO}_{2}$, and compliance.

Surface tension. The amount of phosphatidylcholine present in the alveolar wash samples from lambs treated with natural surfactant was $0.21 \pm 0.02 \mu$ moles $/ \mathrm{ml}$ whereas only $0.008 \pm 0.002$ $\mu \mathrm{moles} / \mathrm{ml}$ of phosphatidylcholine was in the alveolar washes from untreated lambs. The amount of phosphatidylcholine as natural surfactant required to reduce surface tension to less than 10 dynes $/ \mathrm{cm}$ on the surface balance is $0.044 \mu \mathrm{moles} / \mathrm{ml}$. The alveolar washes from lambs sacrificed at birth or just before treatment with surfactant contained only about $1 / 5$ the phosphatidylcholine concentration which as natural surfactant would be required to lower surface tension to $<10$ dynes $/ \mathrm{cm}$. Minimum surface tensions were $>30$ dynes/cm before surfactant therapy. Surface tension decreased to $6.3 \pm 2.9$ dynes $/ \mathrm{cm} 10 \mathrm{~min}$ posttherapy and slowly rose again to $21.6 \pm 4.6$ dynes $/ \mathrm{cm}$ by $3 \mathrm{~h}$ posttherapy (Fig. 2).

Histology. The degree of aeration as assessed by our counting method increased from about $9 \%$ before therapy to $25 \%$ after therapy (Fig. 2). This measurement did not distinguish between unventilated and ventilated pretreatment groups or among posttreatment groups. Lungs from normal full term lambs counted by the same method showed $50 \%$ aeration, which was twice that for premature lambs treated with surfactant. Figure 3 shows representative sections from the lungs of lambs sacrificed at birth, 40 min and $3 \mathrm{~h}$ after treatment with natural surfactant. The lungs of the lambs sacrificed at birth or after $30 \mathrm{~min}$ of mechanical ventilation but before surfactant treatment showed poor aeration with thick cellular alveolar septae. Only minimal destructive changes were evident in lungs of those lambs ventilated for 30 min. After treatment, many sections showed relatively uniform aeration and much thinner alveolar walls. By $3 \mathrm{~h}$ relative overdistention of distal airways alternated closely with atelectasis. Figure 4 shows, at very low magnification, a section of lung that dem-
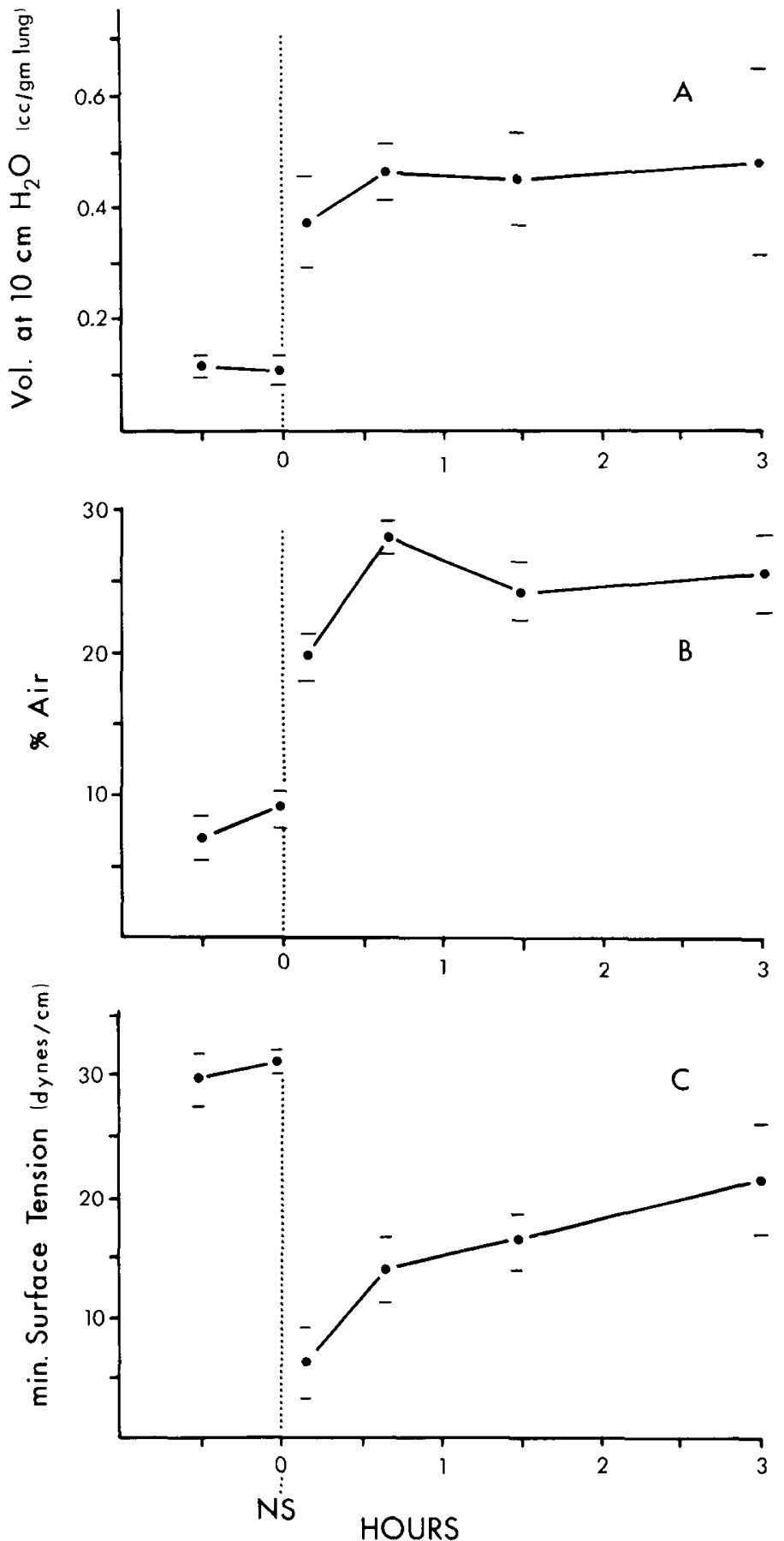

Fig. 2. Comparison of pre- and posttreatment groups. (A) Group mean values \pm S.E. for the volume at $10 \mathrm{~cm} \mathrm{H}_{2} \mathrm{O}$ on the deflation part of the PV curve $v s$ time of sacrifice, with 0 time being the time of treatment with natural surfactant (NS). (B) Group mean values \pm S.E. of $\%$ aeration as assessed by histology $v s$ time. (C) Group mean values \pm S.E. for the minimum surface tensions of alveolar washes vs time.

onstrated the scattered aeration evident in the lungs $3 \mathrm{~h}$ after treatment.

Pressure-volume curves. When all lung weights were plotted against times of sacrifice, there was no statistical change found. Within groups it was found that the heavier lungs held the most air. Hence all measurements of lung volume were corrected for lung weight. Interestingly, the \% of maximum volume retained at $10 \mathrm{~cm} \mathrm{H}_{2} \mathrm{O}$ when plotted against time of sacrifice also showed no statistical change (data not shown).

The mean volume at $10 \mathrm{~cm} / \mathrm{g}$ lung on the deflation curve for 
each group of lambs versus time of sacrifice is shown in Figure 2. There are dramatic increases from pretreatment to posttreatment values; however, all values for the posttreatment groups are similar. The volume at maximum inflation and the area between the inflation and deflation curves (enclosed volume) for each group followed the same pattern as that found for the parameter shown in Figure 2. The significant difference was between pretreatment and posttreatment groups but not among posttreatment groups. Lungs of lambs from pretreatment groups as expected were very noncompliant as assessed by PV curves. Their PV curves were very flat on both the inflation and deflation limbs compared to PV curves of treated animals (data not shown).

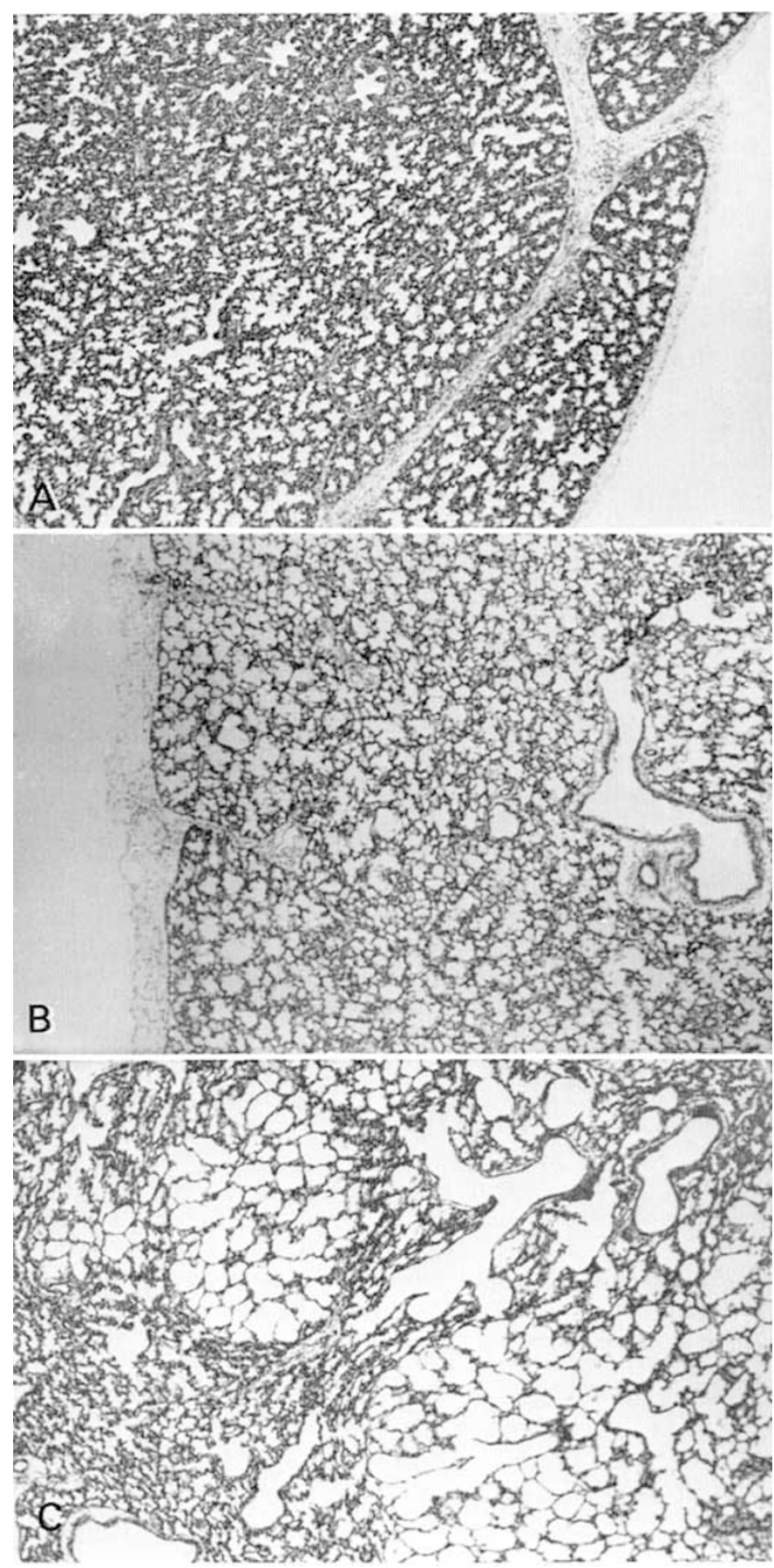

Fig. 3. Selected histologic sections of lung. (A) Section of lung from an unventilated lamb sacrificed at birth. (B) A section from the lung of a lamb sacrificed 40 min after treatment with natural surfactant. (C) Section from lung of lamb sacrificed $3 \mathrm{~h}$ after treatment with natural surfactant.
Correlation of measurements. The PV curve measurements, \% aeration, minimum surface tensions, $\mathrm{PO}_{2}, \mathrm{PCO}_{2}$ and tidal volumes per $\mathrm{g}$ lung were correlated to determine which measurements might best describe the response to natural surfactant treatment (Table 1). Scattergrams were analyzed by linear regression by the method of least squares. The significance of the correlation coefficient for each comparison is given in Table 1. Of particular interest are the high correlations between PV curve parameters and the correlation between minimum surface tension and $\mathrm{PO}_{2}$ at sacrifice.

\section{DISCUSSION}

Lambs born prematurely at 120 days gestational age suffer from a disease process similar to that described for premature infants with $\operatorname{RDS}(9,18,21)$. These lambs have a severe form of this disease as their blood gas and $\mathrm{pH}$ values deteriorated dramatically from birth despite ventilatory support until treatment with natural surfactant. The lambs demonstrated a response to natural surfactant similar to that previously observed $(4,16)$. Surface tensions, PV curves, blood gas measurements and degree of aeration as assessed by histology all improved posttreatment. Subsequent deterioration in blood gas and $\mathrm{pH}$ measurement were all evident by $3 \mathrm{~h}$ after treatment.

Table 1 gives $P$ values for three derived measurements taken in pairs from the PV curves. The three comparisons are all highly significant implying that they are all sensitive measurements of some lung or surfactant characteristic. Because hypoventilation is $\mathrm{PCO}_{2}$ retention, the lambs with the best $\mathrm{PCO}_{2}$ values would be expected to have lungs with the best dynamic compliance. The correlation between simultaneous $\mathrm{PCO}_{2}$ values and tidal volumes/ $\mathrm{g}$ lung (both measured in the live animal) support this. The correlation between the last tidal volume/g lung or $\mathrm{PCO}_{2}$ before sacrifice and the enclosed volume on the PV curve is not significant (Table 1). These relationships demonstrate that PV curves which measure static compliance, may not accurately predict dynamic compliance in the premature lung.

An essential property of surfactant is its ability to lower surface tension at an air-water interface and thus improve lung compliance. Our alveolar wash procedure recovers surfactant from the alveoli. We thus expected that the minimum surface tension measured on the alveolar wash would correlate with the last $\mathrm{PCO}$ and the last tidal volume before sacrifice; however, as is shown in Table 1, this was not the case. In fact, minimum alveolar wash surface tension correlates well with the last $\mathrm{PO}_{2}$ before sacrifice. We retrospectively checked for similar correlations in other 120 day lambs used for a separate study but treated similarly (14). Samples for surface tension measurements from these lambs were obtained by airway suction and analyzed using a dynamic alveolar model (1). The minimum surface tensions were compared with $\mathrm{PCO}_{2}$ and $\mathrm{PO}_{2}$ measurements taken $1-2$ min before the tracheal sampling. As in the present study, the minimum surface tension did not correlate with $\mathrm{PCO}_{2}(\mathrm{P}>0.05)$ but did correlate with $\mathrm{PO}_{2}$ $(\mathrm{P}<0.001)$. Closer inspection of the clinical response curves in Figure 1 and the minimum surface tension curve in Figure 2 reveals that the $\mathrm{PO}_{2}$ rises with the same time course as the fall in surface tension. It is not clear why the compliance and $\mathrm{PCO}_{2}$ did not improve with this time course as well. If the administered surfactant preparation reached the alveoli at a rate predicted by the $\mathrm{PCO}_{2}$ and compliance response, then one might argue that the alveolar wash from group 3 lambs (sacrificed 10 min after treatment) recovered material primarily from airways not involved in gas exchange; however, $\mathrm{CO}_{2}$ is much more diffusable than $\mathrm{O}_{2}$ Thus, if few gas exchange surfaces are coated with surfactant in the first $10 \mathrm{~min}$ and hence made available for that purpose, then it would seem more reasonable for the lambs to still be hypoxic at $10 \mathrm{~min}$ after treatment. There is at present no satisfactory explanation for this. It does appear, however, that the administered surfactant must spread rapidly for the initial severe hypoxia to disappear within $10 \mathrm{~min}$. 


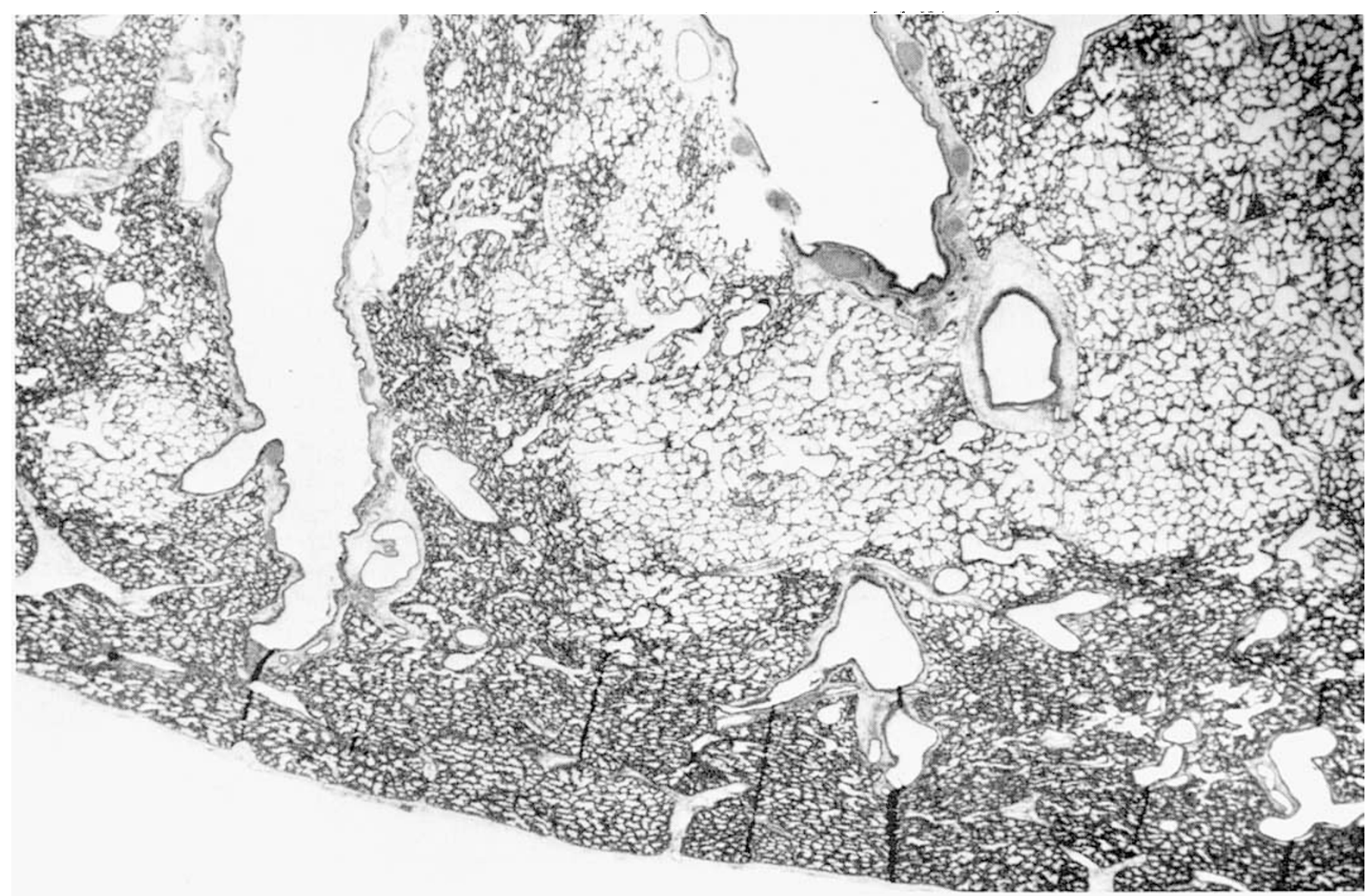

Fig. 4. Large area of lung from a lamb sacrificed $3 \mathrm{~h}$ after surfactant treatment.

Table 1. Correlations of measurements ${ }^{1}$

\begin{tabular}{lcc}
\hline & $P$ & $r$ \\
\hline Residual vol $v s$ vol at $10 \mathrm{~cm} \mathrm{H}{ }_{2} \mathrm{O}$ & $\ll 0.0001$ & +0.93 \\
Residual vol $v s$ enclosed vol & $\ll 0.0001$ & +0.95 \\
Enclosed vol $v s$ vol at $10 \mathrm{~cm} \mathrm{H}{ }_{2} \mathrm{O}$ & $\ll 0.0001$ & +0.94 \\
Tidal vol/g lung $v s \mathrm{Po}_{2}$ & $\mathrm{NS}$ & \\
Tidal vol/g lung $v s \mathrm{PCO}_{2}$ & $\ll 0.0001$ & -0.79 \\
Tidal vol/g lung $v$ \% $\%$ aeration & $\mathrm{NS}$ & \\
Tidal vol/g lung $v s$ enclosed vol & $\mathrm{NS}$ & \\
Tidal vol/g lung $v s$ min surface tension & $\mathrm{NS}$ & \\
Min surface tension $v s \mathrm{PO}_{2}$ & $<0.001$ & -0.74 \\
Min surface tension $v s \mathrm{PCO}_{2}$ & $\mathrm{NS}$ & \\
Min surface tension $v s \%$ aeration & $\mathrm{NS}$ & \\
Min surface tension $v s$ enclosed vol & $\mathrm{NS}$ & \\
Enclosed vol $v s$ PO $\mathrm{O}_{2}$ & $\mathrm{NS}$ & \\
Enclosed vol $v s \mathrm{PCO}_{2}$ & $\mathrm{NS}$ & \\
Enclosed vol $v s \%$ aeration & $<0.02$ & +0.50 \\
\hline
\end{tabular}

Correlation coefficient determined by linear regression using method of least squares for all pairs shown. $P$ values obtained by two tailed Student's $t$ test. NS is not significant $(P>0.05)$. $P$ values are corrected for multiple $t$ tests.

The time delay between sacrifice and completion of the PV curve (about $1 \mathrm{~h}$ ) could have allowed for more even spreading of the surfactant and thus could have accounted for good PV characteristics in lambs sacrificed 10 min after treatment who had high $\mathrm{PCO}_{2}$ values; however, for further spreading of surfactant to be a factor, the material spreading would have to have a low surface tension. Thus one would expect that enclosed volume would correlate with minimum surface tension. As seen in Table 1, there is no such correlation. Furthermore as previously mentioned, there is good reason to believe that most of the spreading of surfactant takes place within 10 min of administration.

The histologic sections appeared to show progressive damage with time, characterized primarily by dilation of distal airways and total atelectasis of alveoli. The tidal volume and thus compliance improved over the first half-hour after surfactant treatment, but the tidal volume did not decrease as the clinical status of the lambs deteriorated. Although the degree of abnormal dilation would be difficult to quantitate, if air filled the progressively abnormal airways then gas exchange would become progressively impaired. Inhibitor(s) of surfactant, which enter the airways and destroy the surface tension lowering properties of surfactant, probably contribute to clinical deterioration (14). Furthermore, the tissue damage might allow for sufficient distensibility even without functional surfactant to achieve the PV characteristics of the excised lungs and aeration seen by histology.

In summary, 120-day-gestational-age lambs in respiratory failure, when treated with natural surfactant, have an abrupt improvement in pulmonary function. Alveolar surface tension and $\mathrm{Po}_{2}$ show an excellent correlation. The apparent progressive dilation of distal airways seen on histologic sections provides an explanation for arterial blood gas and $\mathrm{pH}$ deterioration while the \% aeration in histologic sections and PV curve parameters remain high.

\section{REFERENCES AND NOTES}

1. Adams, F. H. and Enhorning, G.: Surface properties of lung extracts. I. A dynamic alveolar model. Acta Physiol. Scand., 68: 23 (1966).

2. Adams, F. H., Fujiwara. T.. Emmanouilides, G., and Raiha, N.: Lung phospholipids of human fetuses and infants with and without hyaline membrane disease. J. Pediatr., 77: 833 (1970).

3. Adams, F. H., Fujiwara, T., Emmanouilides, G., and Scudder, A.: Surface properties and lipids from lungs of infants with hyaline membrane disease. $J$ Pediatr., 66: 357 (1965).

4. Adams, F. H., Towers, B., Osher, A. B., Ikegami, M., Fujiwara, T., and Nozaki, 
M.: Effects of tracheal instillation of natural surfactant in premature lambs. Clinical and autopsy findings. Pediatr. Res., 12: 841 (1978).

5. Avery, M. E. and Mead, J.: Surface properties in relation to atelectasis and hyaline membrane disease. Am. J. Dis. Child., 97: 517 (1959).

6. Avery, M. E. and Said, S.: Surface phenomena in lungs and health and disease. Medicine, 44: 503 (1965).

7. Bartlett, G. R.: Phosphorus assay in column chromatography. J. Biol. Chem., 234: 466 (1959).

8. Bligh, E. G. and Dyer, W. J.: A rapid method of total lipid extraction and purification. Can. J. Biochem. Physiol., 37: 911 (1959).

9. Brumley, G. W., Chernick, V., Hodson, W. A., Normand, C., Fenner, A., and Avery, M. E.: Correlations of mechanical stability, morphology, pulmonary surfactant and phospholipid content in the developing lamb lung. J. Clin. Invest., 46: 863 (1967)

10. Chu, J., Clements, J. A., Cotton, E. K., Klaus, M. H., Sweet, A. Y., and Tooley, W. H.: Neonatal pulmonary ischemia. Pediatrics, 40: 709 (1967).

11. Enhorning, G., Grossman, G., and Robertson, B.: Pharyngeal deposition of surfactant in the premature rabbit fetus. Biol. Neonate, 22: 126 (1973).

12. Fujiwara, T., Chida, S., Watabe, Y., Maeta, H., Morita, T., and Abe, T.: Artificial surfactant therapy in hyaline-membrane disease. Lancet, $l: 55$ (1980).

13. Ikegami, M., Adams, F. H., Towers, B., and Osher, A. B.: The quantity of natural surfactant necessary to prevent the respiratory distress syndrome in premature lambs. Pediatr. Res., 14: 1082 (1980).

14. Ikegami, M., Jobe, A., and Glatz, T.: Surface activity following natural surfactant treatment of premature lambs. J. Appl. Physiol., 15: 306 (1981).

15. Jobe, A.: The labeling and biological half-life of phosphatidylcholine in subcellular fractions of rabbit lung. Biochim. Biophys. Acta, 489: 440 (1977).
16. Jobe, A., Ikegami, M., Glatz, T., Yoshida, Y., Diakomanolis, E., and Padbury, J.: Duration and characteristics of treatment of premature lambs with natural surfactant. J. Clin. Invest., 67: 370 (1981).

17. Lauweryns, J. M.: Hyaline membrane disease in newborn infants. Human Pathol., l: 175 (1970).

18. Reynolds, E. O. R., Jacobson, H. H., Motoyama, E. K., Kikkawa, Y., Craig, J. M., Oryalesi, M. M., and Cook, C. D.: The effect of immaturity and prenatal asphyxia on the lungs and pulmonary function of newborn lambs. Pediatrics, 35: 382 (1965).

19. Robillard, E., Alarie, Y., Dagenais-Perusse, P., Baril, E., and Guilbeault, A.: Microaerosol administration of synthetic - Dipalmitoyl-L- $\alpha$-Lecithin in the respiratory distress syndrome: A preliminary report. Can. Med. Assoc. J., 90: 55 (1964).

20. Shaffer, T. H., Koen, P. A., Moskowitz, G. D., Ferguson, J. D., and DelivoriaPapadopoulos, M.: Positive end expiratory pressure: effects on lung mechanics of premature lambs. Biol. Neonate, 34: 1 (1978).

21. Stahlman, N., LeQuire, V. S., Young, W. C., Merrill, R. E., Birmingham, R. T., Payne, G. A., and Gray, J.: Pathophysiology of respiratory distress in newborn lambs. Am. J. Dis. Child., I08: 375 (1964).

22. Requests for reprints should be addressed to: Dr. Harris Jacobs, BIdg. A-17, Harbor-UCLA Medical Center, 1000 W. Carson Street, Torrance, CA 90509

23. This research was supported by a grant from the March of Dimes Birth Defects Foundation, by HD-12714 from the Department of Health and Human Development, and by a Research Career Development Award HD-HL-00252 to Alan Jobe.

24. Received for publication August 27, 1981

25. Accepted for publication December 1, 1981. 